\title{
Diminished Actin Polymerization by Neutrophils from Newborn Infants
}

\author{
MARY CATHERINE HARRIS, MEIR SHALIT, AND FREDERICK S. SOUTHWICK \\ Departments of Pediatrics, Immunology and Infectious Disease, University of Pennsylvania School of Medicine, \\ The Children's Hospital of Philadelphia and Hospital of the University of Pennsylvania, \\ Philadelphia, Pennsylvania 19103
}

\begin{abstract}
During the newborn period, abnormalities of neutrophil (PMN) function predispose infants to serious bacterial disease. Actin is a major contributor to PMN shape change and motile behavior. To determine the mechanism underlying defects in newborn granulocyte polarity and chemotaxis, we investigated actin polymerization by cord blood PMN from healthy term infants and adult controls. F-actin (filamentous) content was quantified in the resting state and after stimulation by fluorescenceactivated cell-sorter analysis of nitrobenzoxadiazole-phallacidin-stained cells. PMN from newborn infants demonstrated similar basal F-actin levels when compared with adults. $\mathrm{N}$-formyl methionyl leucyl phenylalanine induced a marked increase in actin polymerization that was maximal at $30 \mathrm{~s}$ in both neonates and adults and that then declined slowly (depolymerization) over the following $10 \mathrm{~min}$. However, the F-actin content of PMN from newborn infants was significantly diminished when compared with adults at 30 and $60 \mathrm{~s}$ after $\mathrm{N}$-formyl methionyl leucyl phenylalanine stimulation $(p<0.05)$. Both the rate and dose response of $\mathrm{N}$-formyl methionyl leucyl phenylalanine-induced actin polymerization were similar for adult and neonatal PMN. PMN from newborn infants also demonstrated significantly diminished actin polymerization when compared with adults $60 \mathrm{~s}$ after stimulation with platelet-activating factor $(p<0.05)$. Decreased concentrations of F-actin may help explain the observed abnormalities of PMN polarity and chemotaxis in healthy newborn infants. (Pediatr Res 33: 27-31, 1993)
\end{abstract}

\section{Abbreviations}

PMN, neutrophil

FMLP, N-formyl methionyl leucyl phenylalanine

PAF, platelet-activating factor

NBD-phallacidin, nitrobenzoxadiazole

FACS, fluorescence-activated cell sorter

During the newborn period, infection remains one of the most significant causes of morbidity and mortality, despite recent advances in neonatal intensive care and the use of broad-spectrum antimicrobial agents $(1-3)$. The increased susceptibility of the newborn infant to bacterial infection is multifactorial, but is principally due to developmental deficiencies of neonatal hostdefense mechanisms $(4,5)$. The PMN represents the most important acute defense against invading bacteria and fungi. Al-

Received July 1, 1992; accepted September 4, 1992.

Correspondence: Mary Catherine Harris, M.D., Division of Neonatology, The Children's Hospital of Philadelphia, 34th Street \& Civic Center Boulevard, Philadelphia, PA 19103. though investigations of newborn PMN function have produced conflicting data, consistently abnormal results have been reported in studies of newborn PMN chemotaxis and polarization $(6,7)$.

Actin is a major contributor to PMN shape change and locomotion $(8,9)$. After stimulation with chemotactic factors, PMN undergo cytoskeletal changes, including a gel-sol transformation involving the rapid polymerization of monomeric G-actin to filamentous F-actin. This change in actin conformation then serves as a framework to generate the force necessary for shape change and motile behavior $(10,11)$. In the newborn infant, then, a decrease in F-actin concentration could help explain the observed abnormalities of PMN polarity and chemotaxis.

We have compared the F-actin content of PMN from healthy newborn infants and adults and found lower concentrations of F-actin in PMN from neonates after stimulation with FMLP or PAF. We determined the rate and concentration dependence of FMLP-induced actin polymerization in neonatal and adult PMN and found them to be similar. We also measured the amount of cytoskeleton-associated actin in PMN from newborn infants and adults and found no significant difference in the concentration of Triton-insoluble actin after FMLP stimulation. Our results suggest that abnormalities of actin polymerization may be partially responsible for the known defects in PMN polarity and chemotaxis in newborn infants.

\section{MATERIALS AND METHODS}

Patient population. The study population consisted of 31 healthy newborn infants enrolled from the Obstetrical Service at the Hospital of the University of Pennsylvania. Blood was obtained by needle aspiration of the umbilical cord after delivery of the fetus but before delivery of the placenta. This procedure was used to minimize leukocyte activation during the collection process. In a few instances, blood was obtained from doubly clamped cord segments at delivery; however, results from the two methods of collection (basal F-actin levels) were not significantly different. Moreover, there were no significant differences in basal F-actin levels in neonates delivered by cesarean section compared with those delivered vaginally. Control blood was obtained from healthy adults routinely used as donors for our laboratory. All blood was processed immediately after collection. On each occasion, PMN from healthy newborn infants were tested simultaneously with an adult control. Clinical characteristics of the study population are shown in Table 1 . This study was performed in accordance with the Human Investigation Committees at the Children's Hospital of Philadelphia and the Hospital of the University of Pennsylvania.

Leukocyte preparation. Leukocytes were separated according to the method developed by Howard and Meyer (10). Whole blood anticoagulated with EDTA was centrifuged at $900 \times g$ for $3 \mathrm{~min}$ at room temperature, and the plasma was removed. The cells were then resuspended in PBS and spun at $1800 \times g$ for 10 
Table 1. Study population*

\begin{tabular}{ccccc}
\hline & Birth wt $(\mathrm{g})$ & Gestation $(w k)$ & Apgar & Mode of delivery \\
\hline Healthy newborn infants $(n=31)$ & $3158 \pm 77$ & $39.6 \pm 0.3$ & $8.1 \pm 0.2(1 \mathrm{~min})$ & $39 \%$ CS, 61\% SVD \\
& & & $9.0 \pm 0.1(5 \mathrm{~min})$ & \\
\hline
\end{tabular}

* Values are mean \pm SEM. CS, cesarean section; SVD, spontaneous vaginal delivery.

min at room temperature, and the buffy coat was collected. Red cells were removed by hypotonic lysis, and the leukocytes were washed and resuspended to $4 \times 10^{6} / \mathrm{mL}$ in modified Hanks' buffer. All leukocyte preparations were then stored at room temperature until use. This method of cell isolation was used to reduce inadvertent stimulation of PMN, which occurs when PMN are subjected to Ficoll-Hypaque or dextran.

PMN F-actin content. PMN F-actin content was determined using flow cytometric analysis of PMN stained with NBD-phallacidin, a fluorescent probe that binds specifically to F-actin (12). Leukocytes were incubated with buffer, FMLP (Sigma Chemical Co., St. Louis, MO) or PAF (Calbiochem Corp., San Diego, CA), at the desired concentration and for the desired length of time. FMLP was prepared as a stock solution of $10^{-2} \mathrm{M}$ in DMSO, frozen, stored in $5-\mu \mathrm{L}$ aliquots at $-70^{\circ} \mathrm{C}$, and diluted in PBS to the desired concentration $\left(5 \times 10^{-6}\right.$ to $\left.5 \times 10^{-12} \mathrm{M}\right)$ just before use. PAF was stored as a stock solution of $10^{-2} \mathrm{M}$ in DMSO and then diluted in PBS to $5 \times 10^{-8} \mathrm{M}$. Incubation times varied from $0 \mathrm{~s}$ to $10 \mathrm{~min}$, depending on the specific experiment performed.

After the incubation with buffer or stimulant, the cells were fixed with $3.7 \%$ formaldehyde for $15 \mathrm{~min}$ at $25^{\circ} \mathrm{C}$, permeabilized with $2.1 \mathrm{mg} / \mathrm{mL}$ L-lysophosphatidylcholine palmitoyl (Sigma), and stained with $3.46 \times 10^{-6} \mathrm{M}$ NBD-phallacidin (Molecular Probes, Eugene, OR) at $37^{\circ} \mathrm{C}$ for $10 \mathrm{~min}$. The cells were then centrifuged at $12000 \times g$ for $1 \mathrm{~min}$ at room temperature and resuspended in buffer.

FACS analysis of NBD-phallacidin-stained cells. F-Actin content was quantified in the resting state and after stimulation by FACS analysis of NBD-phallacidin-stained cells. All cell preparations were analyzed on the Ortho Spectrum III (Ortho Pharmaceutical, Raritan, NJ). Cells were excited with an argon laser at $488 \mathrm{~nm}$, and emission was read at $522 \mathrm{~nm}$. Using the combination of low-angle forward light scatter and $90^{\circ}$ angle light scatter, PMN were gated and mean fluorescence intensity was measured. The conditions used have previously been found to exclude other leukocyte populations from analysis, namely, mononuclear cells, remaining erythrocytes, and debris (13). All intensities of cellular fluorescence were recorded on the linear scale ranging from 0 to 255 channels. Fluorescence histograms plotting cell number (vertical axis) versus fluorescence channel (horizontal axis) were recorded for an average of 5 000-10000 $\mathrm{PMN} /$ sample. Neutrophil F-actin content was expressed as the mean fluorescence intensity of unstimulated or stimulated cells. Unstimulated values were comparable when cells were incubated in modified Hanks' buffer or $0.01 \%$ DMSO in modified Hanks' buffer (experiments with adult cells only). Moreover, previous comparisons of Ficoll-Hypaque purified and mixed-population peak F-actin content have yielded comparable results (14). In most instances, fluorescence histograms yielded a normal distribution of cells (the peak fluorescence channel corresponded to the mean fluorescence). However, one of 31 adult histograms and seven of 31 histograms from newborn infants demonstrated a bimodal PMN distribution with regard to F-actin content.

Triton-insoluble cytoskeleton-associated actin. A modification of the method described by White et al. (15) was used. PMN were purified on Ficoll-Hypaque gradients and resuspended in modified Hanks' buffer. The cells were then centrifuged at 400 $\times g$ at room temperature and resuspended in the same buffer to achieve a final concentration of $1.5 \times 10^{7} \mathrm{PMN} / \mathrm{mL}$. Five hundred $\mu \mathrm{L}$ of the cell suspension were added to $55 \mu \mathrm{L}$ of buffer or $5 \times 10^{-6} \mathrm{M}$ FMLP and incubated for 10 and $40 \mathrm{~s}$ at $37^{\circ} \mathrm{C}$. The reaction was stopped by the addition of $65 \mu \mathrm{L}$ of Tritonstop solution containing $10 \%$ Triton X-100, $7.5 \mathrm{mg} / 100 \mathrm{~mL}$ benzamidine, $4 \mathrm{mg} / 100 \mathrm{~mL}$ aprotinin, $1 \mathrm{mg} / 100 \mathrm{~mL}$ leupeptin, $1 \mathrm{mM}$ phenylmethylsulfonyl fluoride, $54 \mathrm{mM}$ piperazine- $N, N^{\prime}$ bis(2-ethanesulfonic acid), $22.5 \mathrm{mM} \mathrm{N}$-2-hydroxyethylpiperazine- $N^{\prime}$-2-ethanesulfonic acid, $9 \mathrm{mM}$ EGTA, and $1.8 \mathrm{mM}$ $\mathrm{MgCl}_{2}$

The amount of Triton-insoluble cytoskeleton-associated actin was quantified as described previously (16). After mixing by two gentle inversions, the solution was allowed to sit for $2 \mathrm{~min}$ at $25^{\circ} \mathrm{C}$ and then centrifuged for $2 \mathrm{~min}$ at $12000 \times g$ in an Eppendorf centrifuge. The resulting pellet (the Triton-insoluble fraction) was solubilized in $100 \mu \mathrm{L}$ of gel sample buffer containing $8 \mathrm{M}$ urea, $1 \mathrm{~g} / 100 \mathrm{~mL}$ SDS, $2 \mathrm{~g} / 100 \mathrm{~mL}$ B-mercaptoethanol, $10 \mathrm{~g} / 100 \mathrm{~mL}$ sucrose, and $0.06 \mathrm{M}$ Tris-HCL (pH 6.8). The sample was next sonicated for $20-30 \mathrm{~s}$ using a Branson sonifier, model 200, with a tapered micro tip (Branson Sonic Power Co., Danbury, CT), output 3. The samples were immediately boiled for $5 \mathrm{~min}$ and electrophoresed onto $5-15 \%$ polyacrylamide slab gels. Triton-insoluble cytoskeleton-associated actin was determined using a Zeneih Soft Laser Densitometer (Biomed Instruments, Inc., Fullerton, CA) interfaced with an Apple II computer. Results were expressed as the ratio of the areas under the densitometer peaks representing FMLP and control Triton extracts.

Statistics. Clinical characteristics of the study population were determined using means and SEM. Data between patient groups were analyzed using analysis of variance for repeated measures as well as independent and dependent $t$ tests. All data from experiments whose fluorescence histograms yielded a normal PMN distribution were included in the statistical analysis represented in Figures 1, 2, and 4. For experiments showing a bimodal PMN distribution, because each peak approximated a normal distribution, a mean fluorescence was determined for each peak.

\section{RESULTS}

Kinetics of actin polymerization/depolymerization in FMLP stimulated $P M N$. PMN from newborn infants demonstrated similar basal F-actin content when compared with adults: mean channel fluorescence $30.3 \pm 1.8$ (mean \pm SEM) versus $31.1 \pm$ 0.7 , respectively (Fig. 1). FMLP $\left(5 \times 10^{-7} \mathrm{M}\right)$ induced a marked increase in F-actin content (polymerization), which was maximal at $30 \mathrm{~s}$ in PMN from both neonates and adults and which then declined slowly (depolymerization) over the following $10 \mathrm{~min}$. However, the F-actin content of PMN from newborn infants was significantly diminished when compared with adults at $30(p<$ $0.005)$ and $60 \mathrm{~s}(p<0.05)$ after FMLP stimulation $(n=11$ paired experiments).

Rate of FMLP-induced actin polymerization. Analysis of early time points $(0-15 \mathrm{~s})$ in seven paired experiments using $5 \times 10^{-7}$ M FMLP allowed determination of the rate of FMLP-induced actin polymerization (Fig. $1 A$ ). These experiments were performed under identical study conditions and temperatures as noted above. PMN from both neonates and adults demonstrated a rapid increase in actin polymerization during the first $15 \mathrm{~s}$ after FMLP stimulation, which then leveled off slightly as it approached the 30-s peak (data not shown). There was no significant difference in F-actin content between PMN from newborn infants and adults during the first $15 \mathrm{~s}$ after FMLP stimulation. Moreover, the rate of FMLP-induced actin polymerization at 0 $10 \mathrm{~s}$ was similar for adult $(2.9 \pm 0.3 \mathrm{U} / \mathrm{s}$, mean $\pm \mathrm{SEM})$ and neonatal PMN $(2.6 \pm 0.3 \mathrm{U} / \mathrm{s}, p=\mathrm{NS})$.

Dose response of F-actin content to FMLP. To determine whether the diminished F-actin content of neonatal PMN might be related to the dose of chemotactic peptide, we examined 


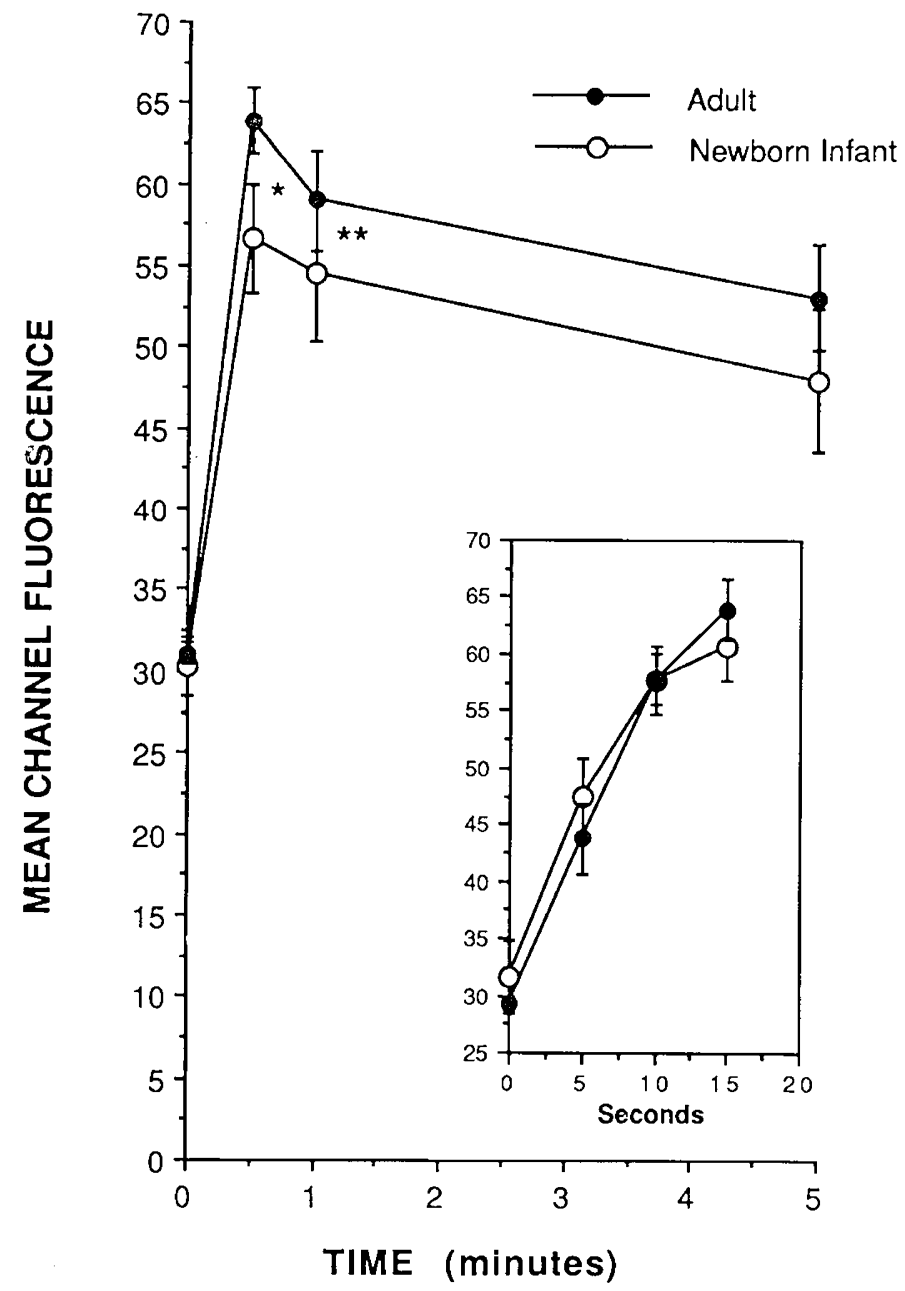

Fig. 1. FMLP-induced $\left(5 \times 10^{-7} \mathrm{M}\right)$ actin polymerization by PMN from newborn infants (-O-) and adults (-—) (mean \pm SEM). ${ }^{*}, p$ $<0.005,30 \mathrm{~s}$ : newborn infants $v s$ adults; ${ }^{* *}, p<0.05,60 \mathrm{~s}$ : newborn infants $v s$ adults. $A$, Rate of FMLP-induced actin polymerization by PMN from newborn infants (-O-) and adults (- - (mean \pm SEM).

FMLP dose-response curves in PMN from newborn infants and adults. In nine paired experiments, PMN exposed to increasing concentrations of FMLP $\left(5 \times 10^{-12}\right.$ to $\left.5 \times 10^{-7} \mathrm{M}\right)$ for $30 \mathrm{~s}$ exhibited progressive increments in $\mathrm{F}$-actin content, which were maximal at $5 \times 10^{-8}$ to $5 \times 10^{-7} \mathrm{M}$ FMLP for both neonatal and adult cells (Fig. 2). However, PMN from newborn infants demonstrated significantly diminished F-actin content when compared with adults after stimulation with $5 \times 10^{-8} \mathrm{M}(p<$ $0.05)$ and $5 \times 10^{-7} \mathrm{M}(p<0.025)$ FMLP (30-s time points).

Analysis of FACS-generated fluorescence histograms in FMLPstimulated $P M N$. When analyzed by FACS, histograms generated by PMN from adults showed a homogeneously distributed singlecell population in the resting state and after FMLP stimulation. Only one of 31 adult histograms suggested a nonhomogeneous distribution of PMN F-actin content. In contrast, histograms from seven of 31 neonates demonstrated two populations of PMN with regard to actin polymerization (Fig. 3). In each case (newborn infant and adult), the cells were distributed homogeneously in the resting state; however, after stimulation, the two cell populations became evident. These PMN subpopulations were observed only after FMLP stimulation. When PAF was used as the stimulus, a homogeneously distributed single-cell population was observed in both the resting and stimulated states. In the seven neonates with nonhomogeneous cell distributions, two peaks of fluorescence intensity were noted after stimulation with $5 \times 10^{-7} \mathrm{M}$ FMLP for $30 \mathrm{~s}$ [mean channel fluorescence: $31.3 \pm 2.4$ (mean \pm SEM) and $63.4 \pm 4.2]$. Moreover, when

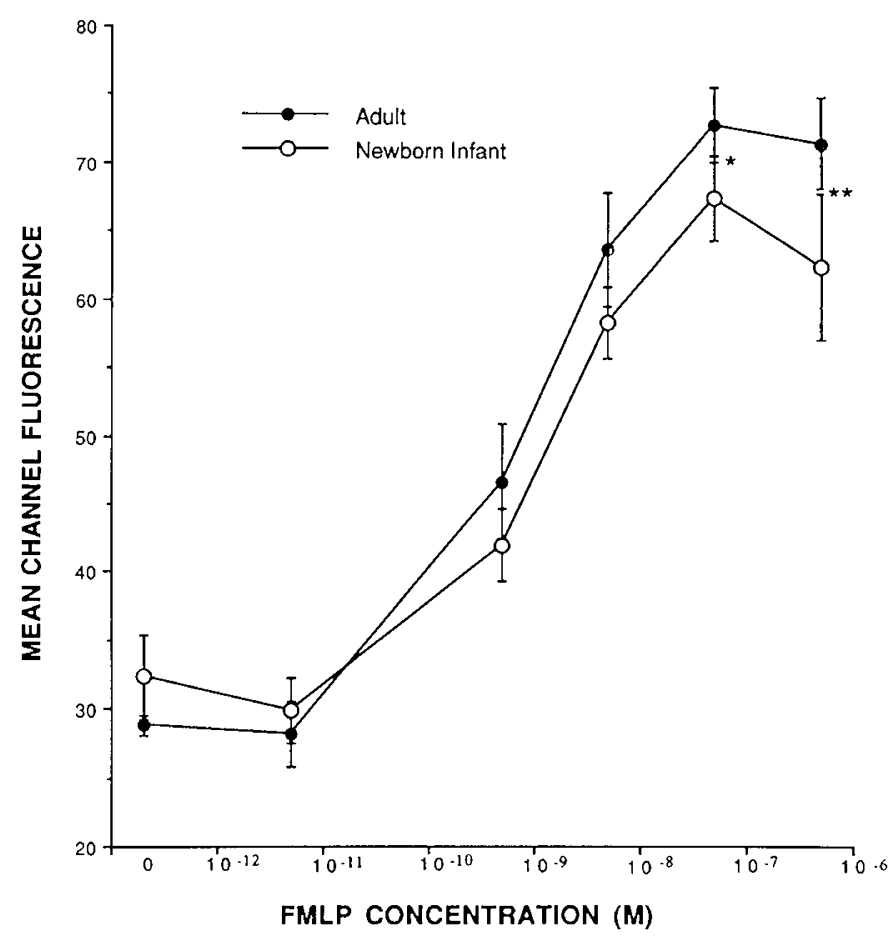

Fig. 2. Dose response of F-actin content to FMLP by PMN from newborn infants $(-\mathrm{O}-)$ and adults $(-\longrightarrow)$ (mean \pm SEM) (30-s time points). ${ }^{*}, p<0.05,5 \times 10^{-8}$ M FMLP: newborn infants $v s$ adults; ${ }^{* *}, p$ $<0.025,5 \times 10^{-7} \mathrm{M}$ FMLP: newborn infants $v s$ adults.

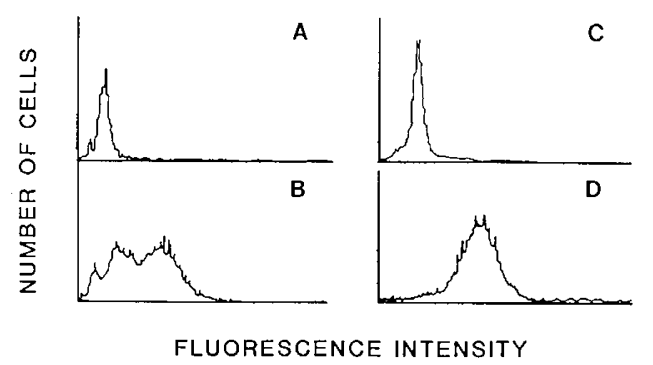

Fig. 3. Histograms of neonatal and adult PMN. Representative fluorescence histograms of neonatal PMN showing a homogeneously distributed single-cell population in the resting state $(A)$ and a bimodal cell distribution after FMLP stimulation $(B)$. Fluorescence histograms of adult PMN showing a homogeneously distributed single-cell population in both the resting state $(C)$ and after FMLP stimulation $(D)$ are shown for comparison.

observed, the two PMN subpopulations were found in all stimulated samples obtained from an infant on a particular day. In addition, adult control PMN examined simultaneously showed no evidence of a bimodal distribution of cells. There was no significant relationship between the presence of PMN subpopulations and timing of blood collection (before or after delivery of the fetus), mode of delivery (vaginal versus cesarean section), birth weight, and Apgar scores.

We have subsequently obtained cord blood samples from an additional 13 healthy, term neonates to examine cell differential counts. These samples contained, on average, $42 \pm 3.3 \%$ (mean \pm SEM) mature PMN, $5.5 \pm 1.3 \%$ bands, $45 \pm 4.1 \%$ lymphocytes, $4.9 \pm 0.4 \%$ monocytes, and $1.6 \pm 0.5 \%$ eosinophils. Although we cannot directly correlate these results to those of our study, it does not appear that cord blood is enriched for immature PMN forms. Previous literature describing cord blood differential counts also supports these findings (17).

Neutrophil F-actin content after stimulation with PAF. To determine whether the diminished F-actin content in neonatal 
PMN might be specific to the stimulus FMLP, we also examined actin polymerization of adult and neonatal PMN after stimulation with PAF. Previous experiments from our laboratory have demonstrated that a concentration of $5 \times 10^{-8} \mathrm{M}$ PAF elicits maximal actin polymerization by adult PMN. As shown previously, PMN from newborn infants demonstrated similar basal F-actin content when compared with adults. In four paired experiments, PAF induced an increase in F-actin content that was maximal at $60 \mathrm{~s}$ in PMN from both neonates and adults and that then declined slowly over $5 \mathrm{~min}$ (Fig. 4). However, the Factin content of PMN from newborn infants (mean channel fluorescence: $45.0 \pm 1.9$ ) was significantly diminished when compared with adults $(52.1 \pm 2.5) 60 \mathrm{~s}$ after PAF stimulation $(p$ $<0.05$ ). These findings suggest that abnormalities of actin polymerization in newborn PMN are not stimulus specific.

Triton-insoluble cytoskeleton-associated actin in FMLP-stimulated PMN. To further investigate abnormalities of neonatal actin polymerization, we measured the amount of cytoskeletonassociated actin in PMN from newborn infants and adults. After stimulation with FMLP, both neonatal and adult PMN demonstrated a significant increase in cytoskeleton-associated actin. However, in eight experiments, there was no significant difference in the amount of cytoskeleton-associated actin from adult $(2.0 \pm 0.2 \mathrm{FMLP} /$ control) (mean $\pm \mathrm{SEM}$ ) or neonatal PMN (1.7 $\pm 0.1)$ at $10 \mathrm{~s}$ or $40 \mathrm{~s}(1.7 \pm 0.2$ versus $1.5 \pm 0.1 \mathrm{FMLP} /$ control $)$ after FMLP stimulation $(p=$ NS). Moreover, comparison of the staining intensity and molecular weights of other polypeptides revealed no significant differences between newborn infants and

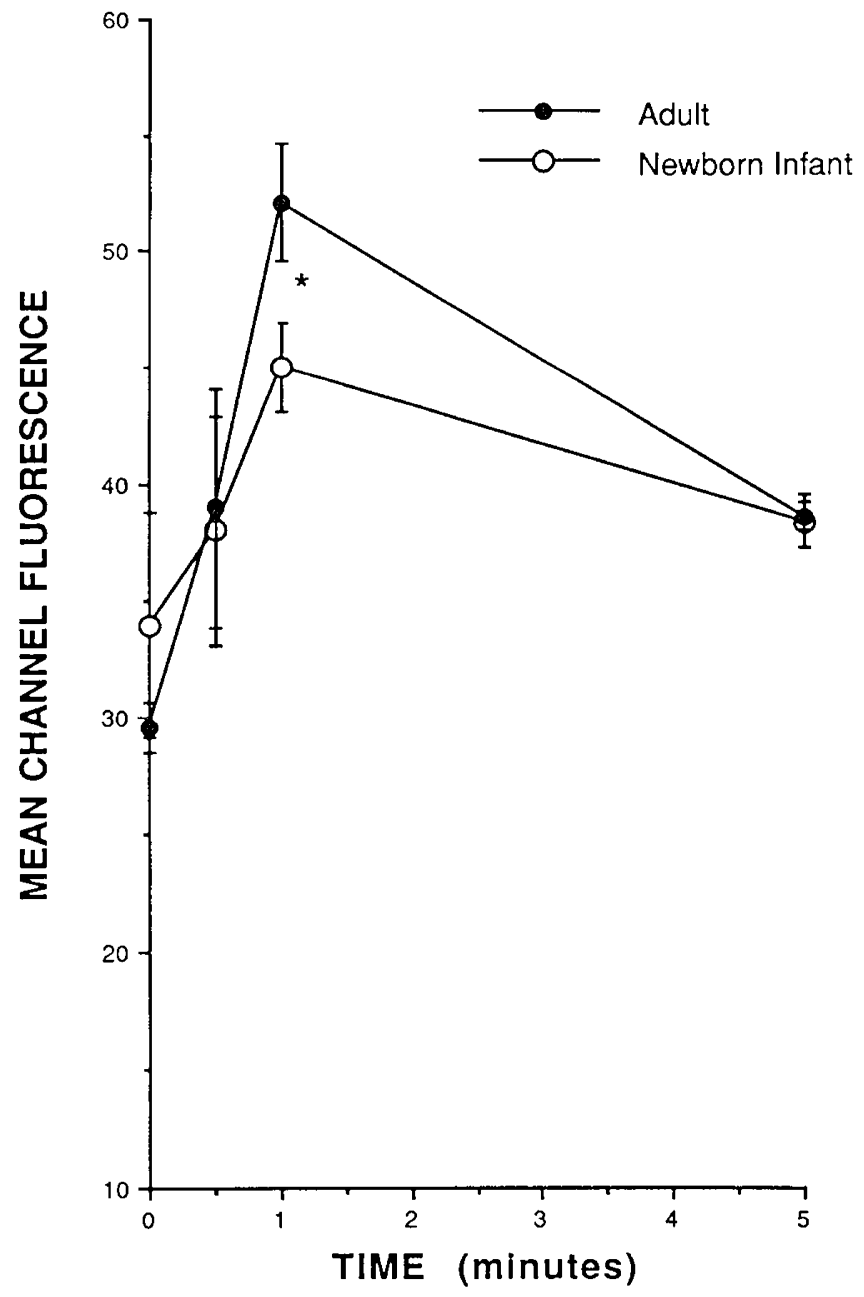

Fig. 4. PMN F-actin content after PAF stimulation in newborn infants $(-\mathrm{O}-)$ and adults $(-\infty)($ mean $\pm \mathrm{SEM}) .{ }^{*}, p<0.05,60 \mathrm{~s}$ : newborn infants $v s$ adults. adults. Figure 5 shows a representative SDS polyacrylamide gel demonstrating actin and other cell-associated proteins. Laser densitometer analysis of the bands is as follows: Neonate: $10 \mathrm{~s}$, $1.9 \mathrm{FMLP} / \mathrm{control} ; 40 \mathrm{~s}, 1.3 \mathrm{FMLP} / \mathrm{control}$. Adult: $10 \mathrm{~s}, 2.8$ FMLP/control; 40 s, 2.3 FMLP/control.

\section{DISCUSSION}

In this study, PMN from newborn infants demonstrated significantly diminished actin polymerization when compared with adults after stimulation with the chemotactic factors FMLP and PAF. However, basal levels of F-actin, the rate of FMLP-induced actin polymerization, and the FMLP concentration eliciting peak PMN responses were similar for adult and neonatal cells. Although FACS-generated histograms uniformly demonstrated a single homogeneous population of adult PMN, a bimodal distribution was observed in seven of 31 preparations of neonatal cells after FMLP stimulation. In contrast to the results of FACS analysis, PMN from newborn infants and adults demonstrated similar quantities of cytoskeleton-associated actin.

Previous studies in adults have measured the F-actin content of PMN using FACS analysis of NBD-phallacidin-stained cells (10-12). NBD-phallacidin is a fluorescent analog of the phallatoxin phallacidin, which binds specifically to F-actin (11). Howard and Meyer (10) have demonstrated that the FMLP-induced increase in F-actin content, as determined by FACS analysis, coincides with a decrease in G-actin and directly correlates with the rate of locomotion of adult PMN. Howard has also shown that F-actin distribution and cell shape are integrally related. In these studies, as PMN changed from a round to a polarized morphology, the F-actin was redistributed from a diffuse to a focal concentration in the lamellipodium of the cell (12).

Hilmo and Howard (18) recently demonstrated elevated basal F-actin levels, but similar stimulated F-actin contents, when PMN from newborn infants were compared with adults. Thus, the relative increase in F-actin content after FMLP stimulation of neonatal cells was diminished when compared with adults, but was secondary to higher baseline $\mathrm{F}$-actin contents in neonatal cells. Our results, in contrast, showed similar basal F-actin levels

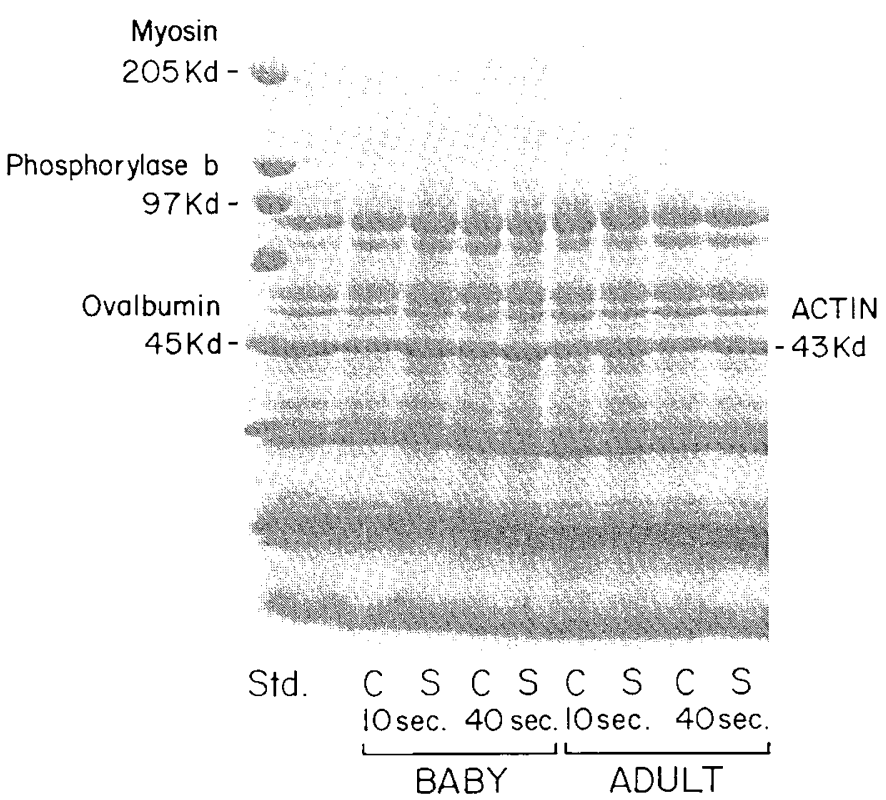

Fig. 5. SDS-polyacrylamide gel of Triton-insoluble cytoskeletons from control and FMLP-stimulated adult and neonatal neutrophils. Lane $I$ represents the standard lane, whereas lane 2 is irrelevant protein. Lanes 3 and 4 and lanes 5 and 6 represent the control $(C)$ and FMLP-stimulated $(S)$ PMN from newborn infants at 10 and $40 \mathrm{~s}$, respectively. Lanes 7 and 8 and lanes 9 and 10 represent control $(C)$ and FMLP-stimulated $(S)$ adult PMN at 10 and $40 \mathrm{~s}$, respectively. 
but decreased stimulated F-actin concentrations in PMN from newborn infants. We obtained most cord blood samples immediately after delivery of the fetus but before delivery of the placenta in an attempt to minimize leukocyte activation during the collection process. Hilmo and Howard (18), in contrast, studied cord or venipuncture blood samples from infants during the first $8 \mathrm{~d}$ of life. Therefore, their studies may represent a somewhat different patient population from those in our investigations. Our results are in closer agreement with those of Sacchi et al. (19), who used a spectrofluorometric assay to correlate abnormalities in actin polymerization with defective chemotaxis in PMN from newborn infants. In these studies, despite similar baseline fluorescence of adult and neonatal cells, PMN from newborn infants failed to generate F-actin after stimulation with FMLP or zymosan-activated serum (19).

In the current study, PMN from only one adult demonstrated a bimodal response with regard to F-actin content; however, PMN from seven newborn infants showed two distinct PMN subpopulations after FMLP stimulation. Our findings contrast with those of Hilmo and Howard (18), who found newborn PMN subpopulations in the resting state, which disappeared after chemotactic factor stimulation. Previous studies in adults have also noted PMN subpopulations that weakly express Fc receptors $(20,21)$, fail to depolarize or hyperpolarize after FMLP stimulation (22), and fail to respond to FMLP with actin polymerization (11). Possible explanations for the PMN heterogeneity and bimodal response include differing stages of PMN maturation, mature but functionally distinct subsets of cells, and/or cell damage during the experimental procedure $(11,23,24)$. Differential counts of neonatal blood samples have failed to demonstrate an enrichment of morphologically immature PMN, making the first possibility less likely. Future studies to clarify the identity of this heterogeneous population of neonatal PMN will require cell sorting followed by additional functional studies.

We have also analyzed the amount of cytoskeleton-associated actin in neonatal PMN. Our results show no significant difference in resting or stimulated levels of F-actin in Triton-insoluble extracts from newborn when compared with adult cells. In contrast to the extremely sensitive FACS analysis, the Triton methodology is far less quantitative, particularly as the gel reaches saturation $(12,15)$. In addition, the Triton assay measures only the F-actin that is bound to the cytoskeleton complex, so that short filaments are not analyzed. Consequently, experiments using the NBD-phallacidin assay and FACS analysis may demonstrate increased amounts of F-actin and differing results when compared with the analysis of Triton-insoluble cytoskeletons.

The mechanisms responsible for the abnormalities of actin polymerization in PMN from newborn infants are unknown. Although basal levels of F-actin were similar in newborn and adult PMN, to date no studies have examined the total intracellular pool of G-and $\mathrm{F}$-actin. Other possible explanations include altered structure or function of the proteins controlling actin filament length (8), abnormalities of signal transduction (calcium mobilization) by neonatal PMN (25), or a deficiency of cellular ATP impairing microfilament contraction (5). In this regard, Sacchi et al. (19) recently demonstrated defective membrane polarization and lower levels of intracellular free calcium in neonatal PMN. Recent studies have also suggested that abnormalities of neonatal PMN function may be responsive to pharmacologic modulation by pentoxifylline, an agent thought to enhance cell deformability (26-28). In these studies, pentoxifylline increased cell fluidity and decreased levels of $F$-actin in neonatal PMN $(26,27)$. Future studies should explore in greater detail the mechanisms responsible for defective actin polymerization by neonatal PMN as well as potential pharmacologic modification of neonatal cellular responses.

In conclusion, PMN from newborn infants demonstrated significantly diminished actin polymerization when compared with adults after chemotactic factor stimulation. This phenomenon was not secondary to an altered rate or dose response of actin polymerization and was not stimulus specific. PMN from newborn infants also demonstrated heterogeneity in their ability to polymerize actin. We speculate that decreased concentrations of F-actin may help explain the observed abnormalities of PMN locomotion and polarity in healthy newborn infants.

\section{REFERENCES}

1. Harris MC, Polin RA 1983 Neonatal septicemia. Pediatr Clin North Am 30: 243-258

2. Siegel JD, McCracken Jr GH 1981 Sepsis neonatorum. N Engl J Med 304: $642-647$

3. Klein JO, March SM 1990 Infectious Diseases of the Fetus and Newborn Infant. Saunders, Philadelphia, pp 601-656

4. Miller ME 1978 Host Defenses in the Human Neonate. Grune \& Stratton, New York, pp 59-71

5. Hill HR 1987 Biochemical, structural and functional abnormalities of polymorphonuclear leukocytes in the neonate. Pediatr Res 22:375-382

6. Anderson DC, Hughes BJ, Smith CW 1981 Abnormal motility of neonatal polymorphonuclear leukocytes: relationship to impaired distribution of surface adhesion sites by chemotactic factor or colchicine. J Clin Invest 68 : 863-874

7. Harris MC, Douglas SD 1986 Neutrophil locomotion and polarity in "stressed" and healthy infants. Pediatr Res 20:389(abstr)

8. Southwick FS, Stossel TP 1983 Contractile proteins in leukocyte function. Semin Hematol 20:305-321

9. Snyderman R, Goetzl EJ 1981 Molecular and cellular mechanisms of leukocyte chemotaxis. Science 213:830-837

10. Howard TH, Meyer WH 1984 Chemotactic peptide modulation of actin assembly and locomotion in neutrophils. J Cell Biol 98:1265-1271

11. Wallace PJ, Wersto RP, Packman CH, Lechtman MA 1984 Chemotactic peptide-induced changes in neutrophil actin conformation. J Cell Biol 99: 1060-1065

12. Howard TH, Oresajo CO 1985 The kinetics of chemotactic peptide-induced change in F-actin content, F-actin distribution and the shape of neutrophils. J Cell Biol 101:1078-1085

13. Shalit M, Dabiri GA, Southwick FS 1987 Platelet-activating factor both stimulates and "primes" human polymorphonuclear leukocyte actin filament assembly. Blood 70:1921-1927

14. Brennan PJ, Zigmond SH, Schreiber AD, Smith ER, Southwick FS 1991 Binding of IgG containing immune complexes to human neutrophil Fc $\gamma$ RII and Fc $\gamma$ RIII induces actin polymerization by a pertussis toxin-insensitive transduction pathway. J Immunol 146:4282-4288

15. White JR, Naccache PH, Sha'afi RI 1982 The synthetic chemotactic peptide formyl-methionyl-leucyl-phenylalanine causes an increase in actin associated with the cytoskeleton in rabbit neutrophils. Biochem Biophys Res Commun 108:1144-1149.

16. Southwick FS, Dabiri GA, Stossel TP 1988 Neutrophil actin dysfunction is a genetic disorder associated with partial impairment of neutrophil actin assembly in three family members. J Clin Invest 82:1525-1531

17. Dorros G, Kleiner GJ, Romney SL 1969 Fetal leukocyte pattern in premature rupture of amniotic membranes and in normal and abnormal labor. Am J Obstet Gynecol 105:1269-1273

18. Hilmo A, Howard TH $1987 \mathrm{~F}$-actin content of neonate and adult neutrophils. Blood 69:945-949

19. Sacchi F, Augustine NH, Coello MM, Morris ER, Hill HR 1987 Abnormality in actin polymerization associated with defective chemotaxis in neutrophils from neonates. Int Arch Allergy Appl Immunol 84:32-39

20. Klempner MS, Gallin JI 1978 Separation and functional characterization of human neutrophil subpopulations. Blood 51:659-669

21. Gallin J 1984 Neutrophil heterogeneity exists, but is it meaningful? Blood 63: 977-983

22. Seligmann B, Chused TM, Gallin JI 1981 Human neutrophil heterogeneity identified using flow microfluorometry to monitor membrane potential. $J$ Clin Invest 68:1125-1131

23. Krause PJ, Malech HL, Kristie J, Kosciol CM, Hesson VC, Eisenfeld L, Patuzak WT, Krause A, Seligmann B 1986 Polymorphonuclear leukocyte heterogeneity in neonates and adults. Blood 68:200-204

24. Harvath L, Leonard EJ 1982 Two neutrophil populations in human blood with different chemotactic activities: separation and chemoattractant binding. Infect Immun 36:443-449

25. Korchak HM, Rutherford LE, Weissman G 1984 Stimulus response coupling in the human neutrophil. I. Kinetic analysis of changes in calcium permeability. J Biol Chem 259:4070-4075

26. Krause PJ, Maderazo EG, Contrino J, Eisenfeld L, Herson VC, Greca N, Bannon P, Kreutze DL 1991 Modulation of neonatal neutrophil function by pentoxifylline. Pediatr Res 29:123-127

27. Newton JA, Ashwood ER, Yang KD, Augustine NH, Hill HR 1989 Effect of pentoxifylline on developmental changes in neutrophil cell surface mobility and membrane fluidity. J Cell Physiol 140:427-431

28. Rao KMK, Crawford J, Currie MS, Cohen HJ 1988 Actin depolymerization and inhibition of capping induced by pentoxifylline in human lymphocytes and neutrophils. J Cell Physiol 137:577-582 